\title{
ARQUITETURA DAS ÁRVORES: CONSTRUINDO COM A NATUREZA
}

\section{Jualiana Castro \\ Arquiteta graduada na Universidade Federal de Santa Catarina}

Alina Santiago

Doutora, arquiteta, professora do Departamento de Arquitetura e Urbanismo da Universidade Federal de Santa Catarina

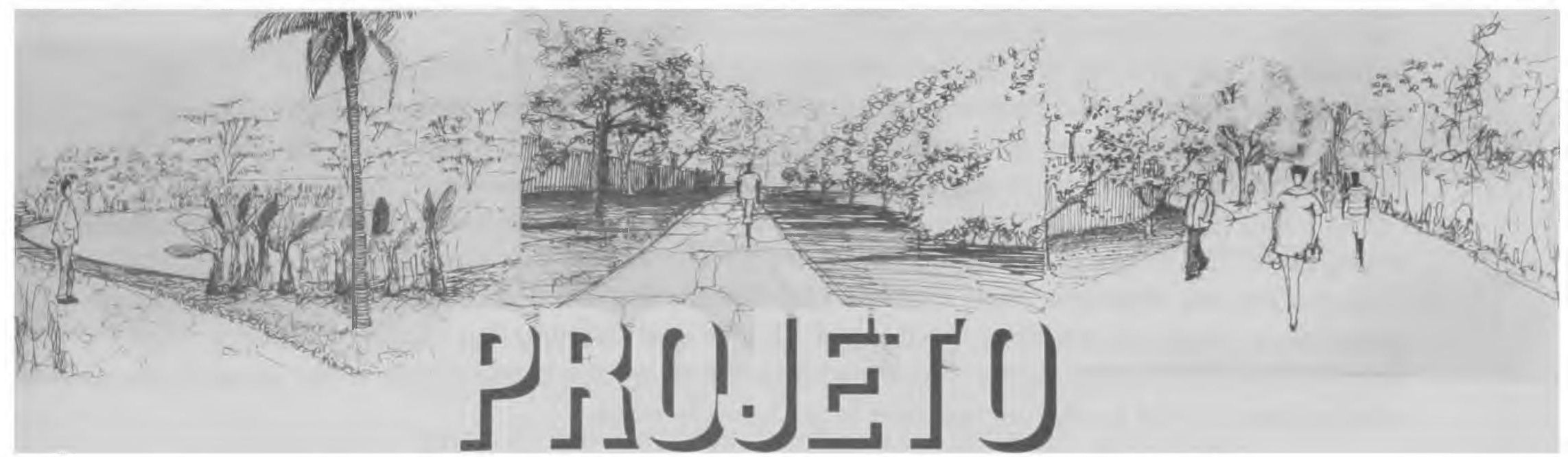


Desde o início dos tempos o ser humano teve necessidade de transformar a natureza, afastandose de sua forma natural de organização. Atualmente, a necessidade do contato direto permanece, mesmo com a grande distância imposta pela criação das cidades, porque faz parte da condição humana.

Os jardins foram inventados pelo homem para realizar esta relação, ficando a meio caminho entre a beleza espontânea das formas naturais e o ato de ordenação e simplificação da realidade que requer a percepção humana. Eles são a expressão arquitetônica do homem pelos elementos naturais.

Este trabalho objetiva estudar as formas vegetais e compreendê-las como instrumentos de produção da arquitetura, simulando diferentes situações de projeto relacionadas à composição da paisagem. Para estudo e aplicação de uma metodologia de projeto foi desenvolvido como estudo de caso a proposta de um jardim botânico para a cidade de Florianópolis/SC. A idéia de projetar um jardim botânico surgiu ao se pensar que este espaço possibilita não só o contato dos seres humanos com a natureza por meio do lazer, mas também pela ciência, sendo necessária a criação de ambientes formados por grupos vegetais específicos, aumentando a diversidade de situações projetuais.

Primeiramente foram definidas e estudadas formas de composição vegetal em relação a elementos isolados e conjuntos, associando a utilização da vegetação à percepção que se deseja que as pessoas tenham de cada espaço determinado de forma genérica.

Pela aplicação dos parâmetros compositivos foram simuladas diferentes situações de projeto por meio de croquis, criando os ambientes desejados e definindo a partir daí as espécies vegetais que se adequassem melhor à composição escolhida. Para escolher as espécies foram criados parâmetros de classificação relacionados a características formais, funcionais e temporais de cada elemento.

\section{ABSTRACT}

Human beings have always needed to modify the nature, keeping themselves away from its natural organization. Nowadays the necessity for direct contact remains - even with the distance imposed by the creation of cities - because its part of human condition.

Gardens were created to establish this relation, which mediates spontaneous beauty of natural shapes and ordination act that requires human perception. Gardens are human architecture expression through natural elements.

This work aims at studying and understanding the natural elements as architecture production tools. Simulating different project situations associated with landscape composition.

In order to study and apply a methodology, a Botanical Garden was designed. Botanical garden was chosen as case study because it allows not only the contact between human being and nature for leisure, but also for research matters. Due to the scientific purpose designing project becomes more complex since specific vegetal species have to be used.

Firstly, forms of vegetal composition were defined. These forms were related with isolated elements and groups. The usage of plants was associated with desired perception to which place.

Different project situations were simulated by the application of composite parameters through perspective drawings, creating the desired places and defining the vegetable species that fits better to the chosen composition. Classification patterns were created to choose the vegetal species relating them to the form, function and time characteristics. 


\section{ARQUITETURA DAS ÁRVORES: CONSTRUINDO COM A NATUREZA}

\section{O Homem e a Natureza}

Disse Thoreau que "a natureza não é um cenário impessoal a emoldurar o homem, mas o alvo de uma experiência pessoal e direta, alicerçada na emoção". Para ele, o homem não está acima da natureza, mas é parte integrante dela.

A construção da arquitetura por meio dos elementos da natureza está associada a um conjunto de fatores importantes que muitas vezes extrapolam as decisões estéticas de projeto. É necessário considerar, principalmente, que no caso da vegetação cada elemento compositivo do espaço, independentemente de seus atributos formais, é um ser vivo que está sujeito a transformações, as quais podem inclusive modificar estes atributos.

Segundo Leenhardt, "Para o passeante, os elementos compositivos da paisagem tornam-se traços significativos e pertinentes, que marcam sua consciência. Podem provir do trabalho da memória bem como dos movimentos de seu corpo. Tal forma captada de realce, tal flor, tal árvore, adquirirão assim, num instante aberto por uma disponibilidade do espírito e dos sentidos, uma autonomia e uma singularidade que as retirarão por um tempo de toda a visão de conjunto (...) A organização espacial dos elementos tem como função primeira ritmar o passeio, tomando como medida a alternância do andar e do repouso, da deambulação e das paradas (... ) Seu passeio será construído no tempo como uma alternância nas percepções estruturadas por pontos de vista escolhidos e o desfilar de seqüências visuais captadas sob ângulos em perpétua modificação."

Para Brecht, "A riqueza da experiência estética de um espaço no qual o passeante se desloca implica, com efeito, que se entrechoquem, em sua consciência e em seu corpo, os diferentes níveis de sua percepção. Como no teatro, é mister que ele se sinta parte integrante do espetácu10, ser vivo entre os seres vivos, mas é preciso dar-lhe também, ao mesmo tempo e contraditoriamente, o sentimento de que assiste ao espetáculo ( ... ). O duplo registro da visão e da experiência do corpo constitui portanto, em seu caráter paradoxal, o próprio fundamento de uma verdadeira estética da paisagem e do jardim." 
Partindo destes pressupostos, neste projeto se buscou estudar composição de espaços arquitetônicos pelos elementos vegetais que permitam a realização destas experiências sensoriais, explorando as possibilidades de aproximação amena do homem com o mundo natural, de modo que o prazer desta convivência venha a suscitar o entendimento de um futuro com mais respeito à natureza.

\section{Objetivos}

\subsection{Objetivo Principal}

O objetivo principal deste trabalho foi estudar as formas vegetais e compreendê-las como um instrumento de produção da arquitetura. Estudar seus atributos formais individualmente e em conjunto, simulando diferentes situações de projeto.

\subsection{Objetivos Específicos}

2.2.1 Valorizar os aspectos sensitivos do usuário pela dinamicidade proporcionada pela diversidade da vegetação e suas transformações naturais durante as estações.

2.2.2. Trabalhar com a maior diversidade de espécies possível, dando preferência à exploração das plantas nativas para despertar seu uso como vegetação ornamental.

2.2.3. Realização de um estudo de caso: Projeto de um jardim botânico para a cidade de Florianópolis.

\section{Metodologia de Abordagem}

\subsection{Contextualização}

- Estudo da temática abordada a partir de uma análise documental.

- Definição de padrões de composição vegetal e atributos de classificação das espécies relacionados à sua forma, função e comportamento temporal, objetivando criar uma base teórica para a definição dos espaços arquitetônicos.

\subsection{Estudo Preliminar}

- Compreensão da área da proposta por meio da identificação de setores diferenciados pela elaboração de um programa de necessidades. 
- Definição de critérios de dimensionamento dos espaços a fim de identificar lugares diferenciados, uma vez que os condicionantes físicos e as funções desejadas não são os mesmos para todos os locais.

- A partir desta identificação é lançado um primeiro zoneamento da área da proposta.

\subsection{Estudos de Caso}

- Simulação de diferentes composições vegetais para cada zona definida na fase anterior, levando em conta a forma dos elementos vegetais, seus atributos sinestésicos e seu ciclo natural de vida, definidos na primeira etapa do trabalho. Consideramos que esta é a fase mais importante de todo o trabalho, uma vez que seu principal interesse é a simulação de formas de composição de um espaço arquitetônico por meio da vegetação.

\subsection{Definição dos Espaços}

- Esta etapa consiste na escolha e adequação das alternativas propostas nos estudos de caso para as zonas definidas no estudo preliminar, definindo uma primeira idéia de implantação para o local.

- Nesta etapa são definidas também as espécies mais indicadas para cada situação, realizando-se o anteprojeto paisagístico.

\section{Resultados}

\subsection{A Construção da Paisagem}

Para compor uma paisagem é necessário que se tenha em mente algumas leis de composição que definam de forma clara os efeitos que se deseja criar. Segundo Tapia, as árvores são os elementos vegetais estruturadores da paisagem. São elas que armam o cenário, conformam e delimitam o espaço exterior. São vegetais de grande porte que expressam de forma sintética toda a força e a complexidade da natureza.

\subsubsection{Definição de Padrōes Compositivos}

1. Elementos Isolados: Uso das árvores como esculturas. São utilizadas espécies com características morfológicas fortes e deve-se deixar em volta espaço suficiente para que haja destaque do elemento. Este tipo de estratégia compositiva permite definir marcações e criar referenciais. São privilegiados os valores individuais de magnitude do elemento, sendo a escala do objeto (a árvore) compatível com a de seu entorno. 


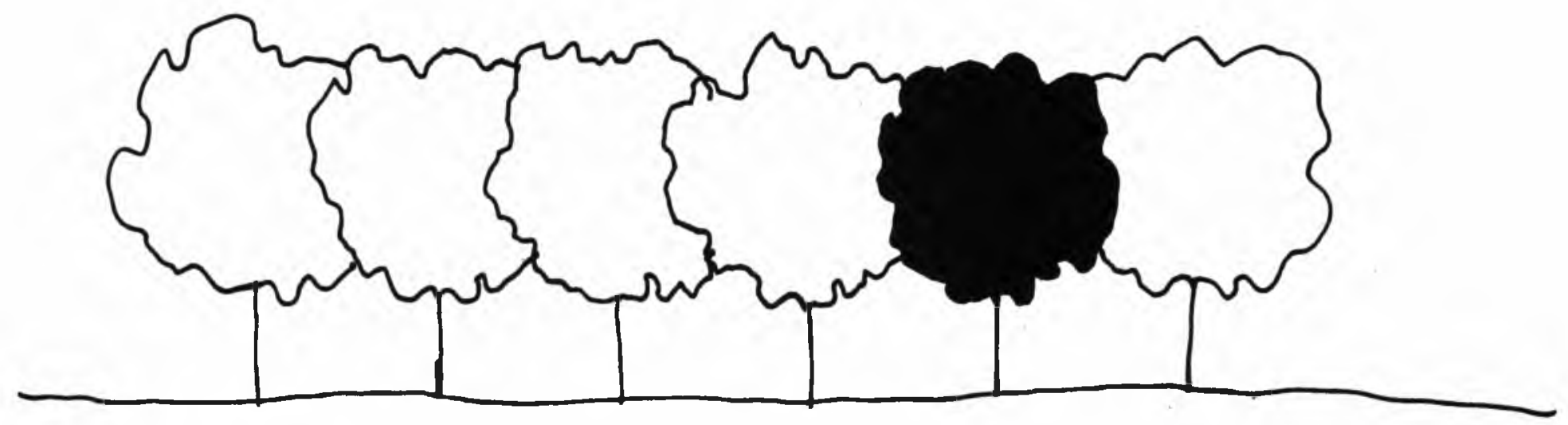

Destaque em relação à cor

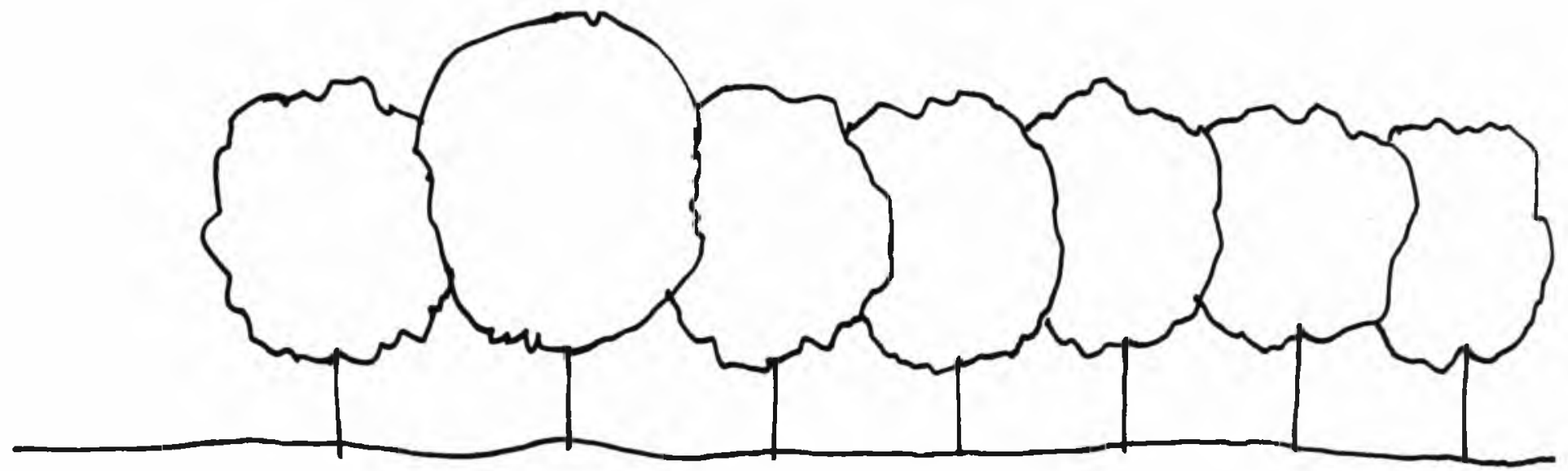

Destaque em relação ao tamanho

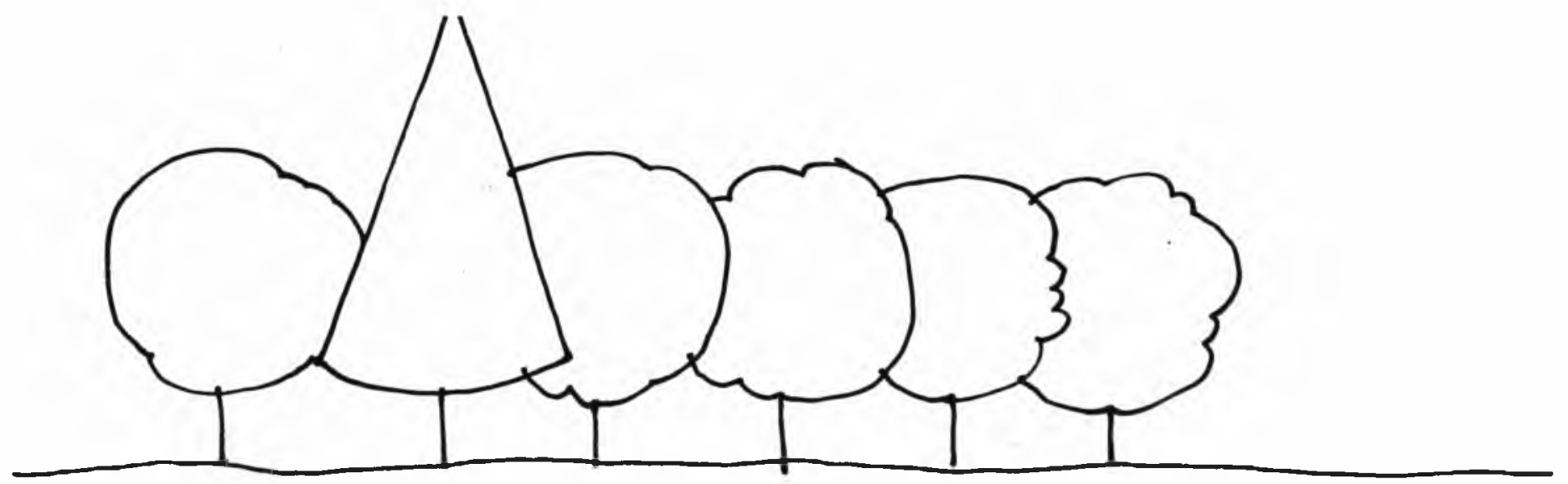

Destaque em relação ò forma

2. Grupos: Considerar os subgrupos que formam o conjunto e usar sempre as mesmas leis de composição. Mesmo que cada elemento do conjunto tenha característica formal individual marcante, o que deve predominar é a característica formada pelo conjunto. É importante evitar o uso de grupos com características morfológicas semelhantes para que estes não se confundam, prejudicando a legibilidade da composição do grupo. 


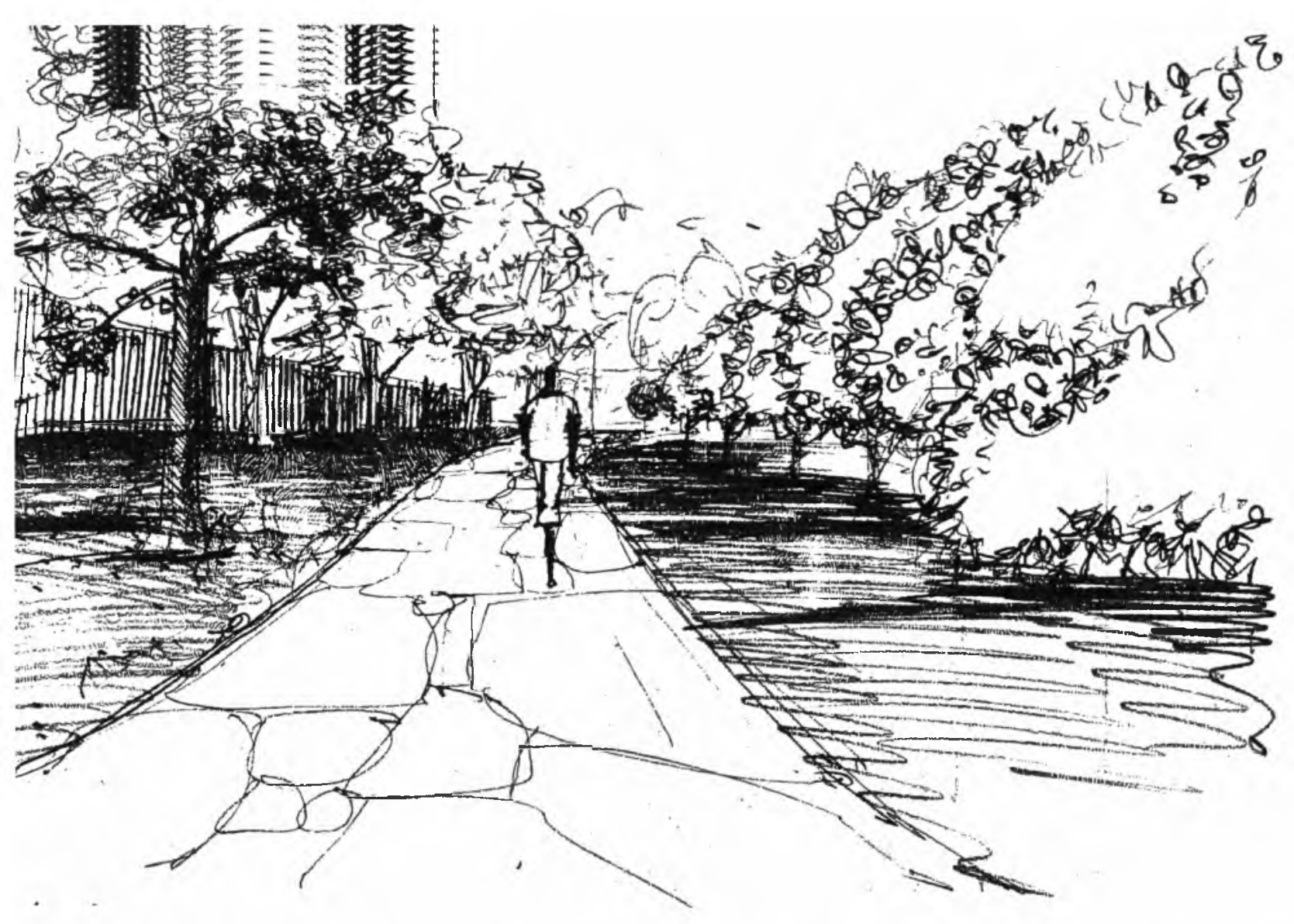

Agrupamento em linho ręta

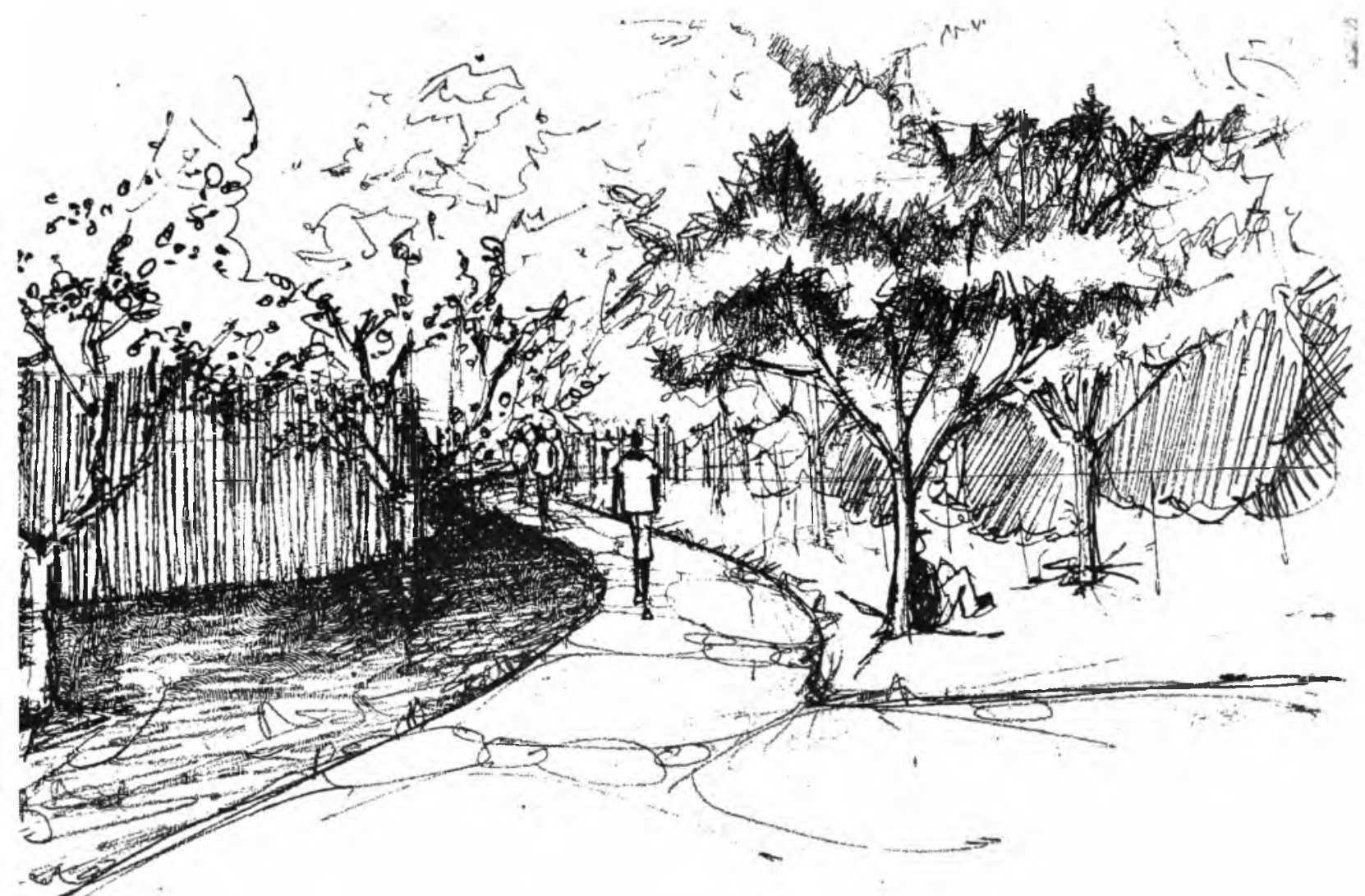

Agrupamento em linha curva

3. Organização de maciços: Maciços são grupos formados por vários grupos ou subconjuntos, nos quais a relação predominante é a de fundo-figura. O resultado das composições grupais são determinantes para a organização de maciços. Este tipo de organização se dá de acordo com leis de domínio e subordinação, em que a relação entre o tamanho de cada grupo e a totalidade do conjunto é de fundamental importância. 


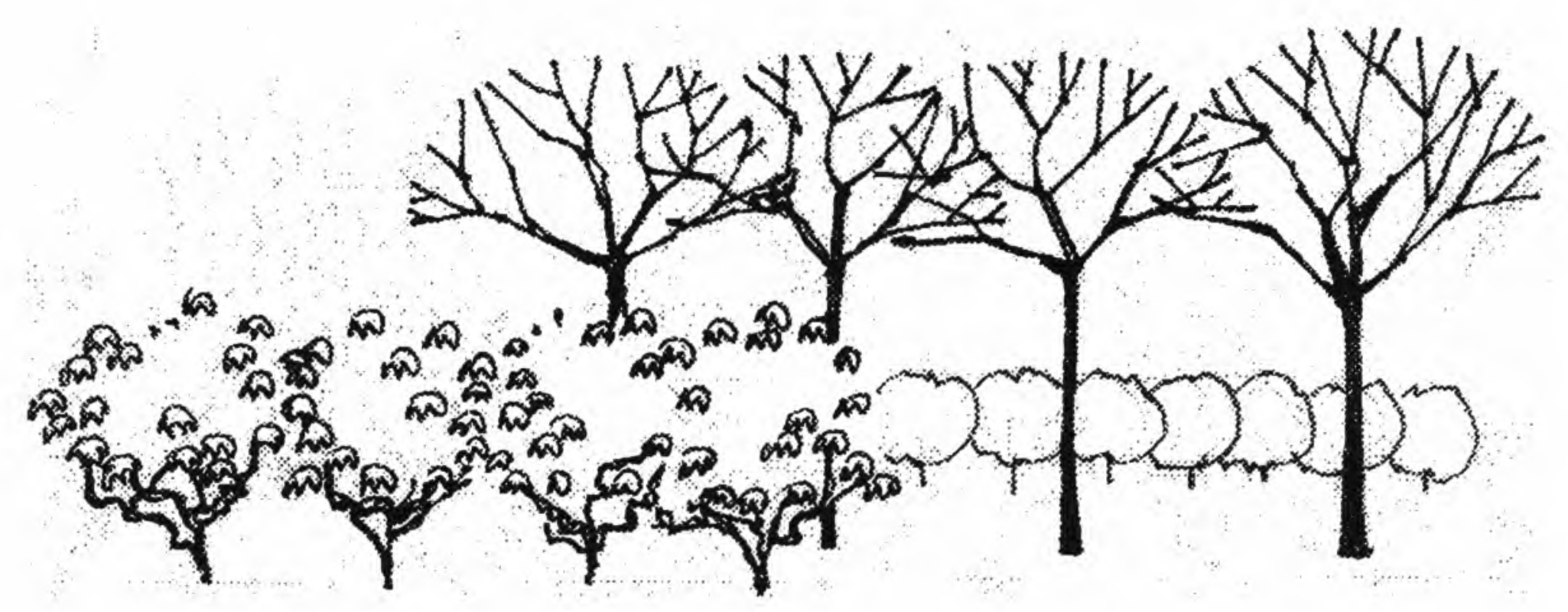

Composição de maciços em fundo-figura

Pela aplicação dos parâmetros compositivos foram simulados diferentes situações de projeto por meio de croquis, criando os ambientes desejados de forma genérica, e definindo a partir daí as espécies arbóreas que se adequassem melhor à composição escolhida. Para escolher as espécies foram criados parâmetros de classificação relacionados às características importantes para a escolha.

\subsubsection{Parâmetros de Classificação dos Elementos Vegetais}

Atributos Formais:

Geometria (Relação entre a altura e o tamanho da copa)

Cor (do tronco, da folhagem, dos frutos e das flores)

Textura (da copa e do tronco)

Atributos Funcionais:

Sombreamento

Capacidade de atração da fauna

Emissão de odores

Emissão de sons (passáros e vento)

Atributos Temporais:

Velocidade de crescimento

102 Perenidade das folhas

Época de floração e frutificação 

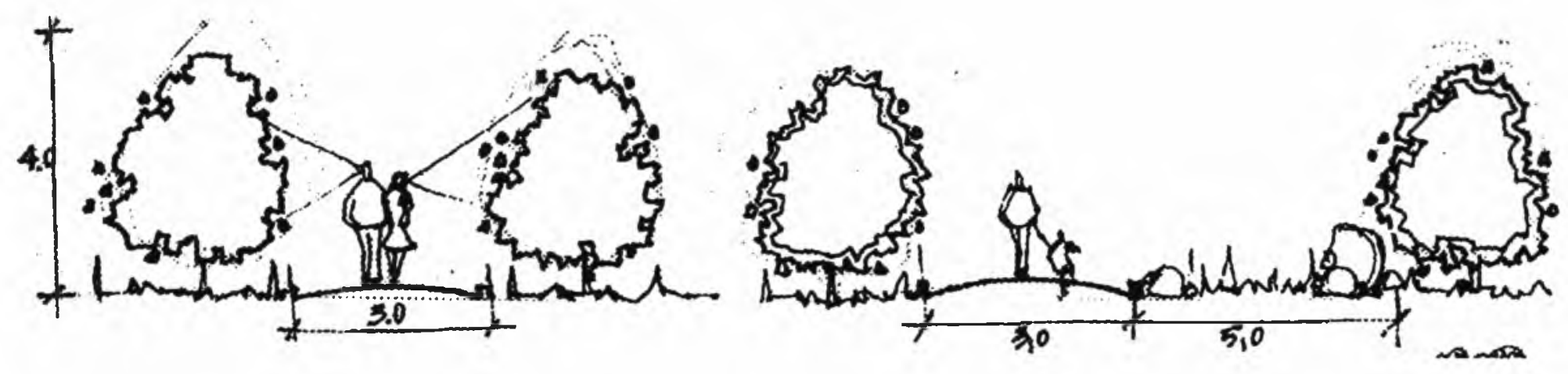

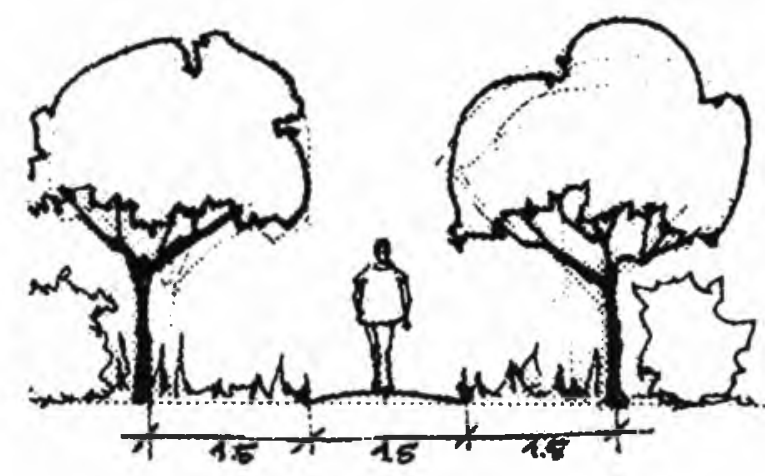

Envolvimento com liberdade de movimentos
Envolvimento com liberdade visual

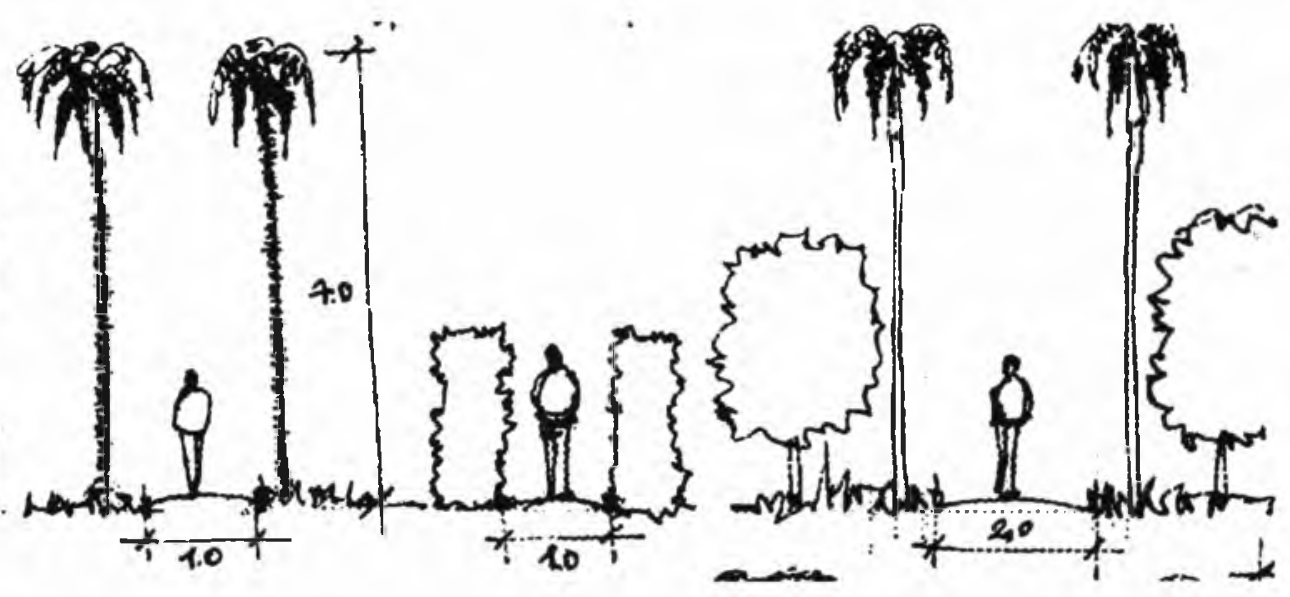

Opressão

Opressão

\subsection{Tempo}

A dimensão do tempo é um fator determinante no projeto de um jardim. Ela atua em diversas escalas, desde a mutação que a paisagem natural pode sofrer no decorrer de um dia - pela variação natural de intensidade da luz em determinados horários e pelas intempéries - até as diferenças provocadas pelo ciclo natural de mudança de estações. E ainda, ao longo dos anos, pelo crescimento e longevidade da vegetação. Segundo Leenhardt, dificilmente podemos falar em um estado definitivo quando se trata de um jardim, visto que a duração de vida de cada espécie é diferente e será preciso continuamente podar, cortar e replantar.

A floração e frutificação das espécies, bem como a perenidade das folhas são fatores decisivos na criação dos ambientes. Podemos 
definir como será cada um destes lugares agrupando a vegetação de acordo com a mutação de suas cores ao longo do ano, compondo tanto com o colorido das flores e frutos quanto com os diferentes tons de verde das folhas. Como quem pintasse um quadro.

Outras transformações relacionadas ao passar do tempo também influem nas decisões projetuais. É necessário que seja levado em conta o tempo de crescimento das espécies. Para tanto se devé prever não só a substituição das espécies de vida mais curta, mas também como se ocupar o lugar daquelas que vão demorar 30,50 ou 100 anos para chegar à idade adulta.

\section{Estudos Hipotéticos}

As figuras abaixo são exemplos de estudos hipotéticos para uma das áreas zoneadas no projeto do jardim botânico. Foram simuladas para cada área diversas alternativas de composição do espaço, sendo escolhidas as mais adequadas à situação projetual desejada, como descrito na terceira etapa da metodologia de abordagem (item 3.3).

\section{Composições Escolhidas}

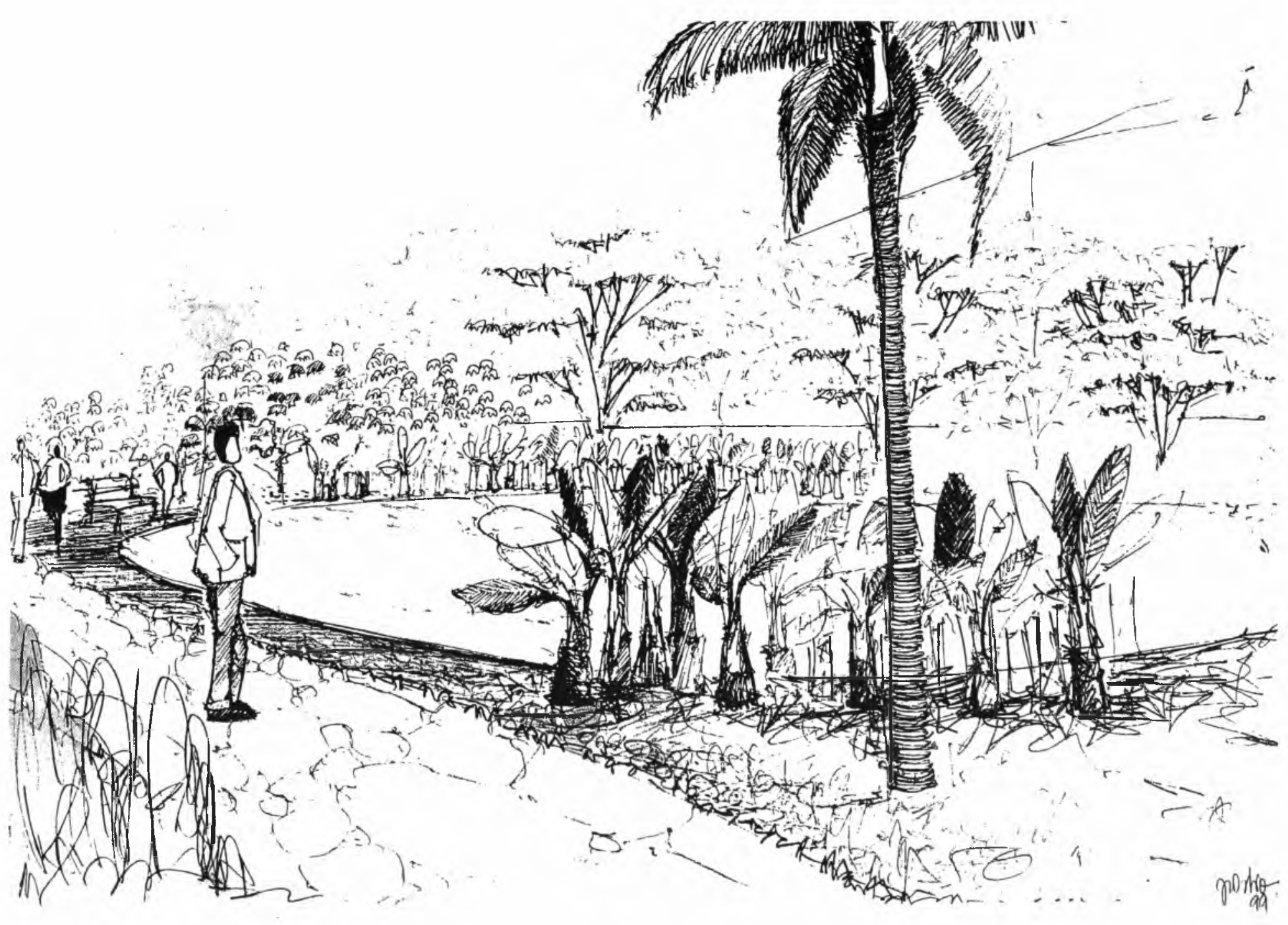

Lago da Frente: Composição de maciços 


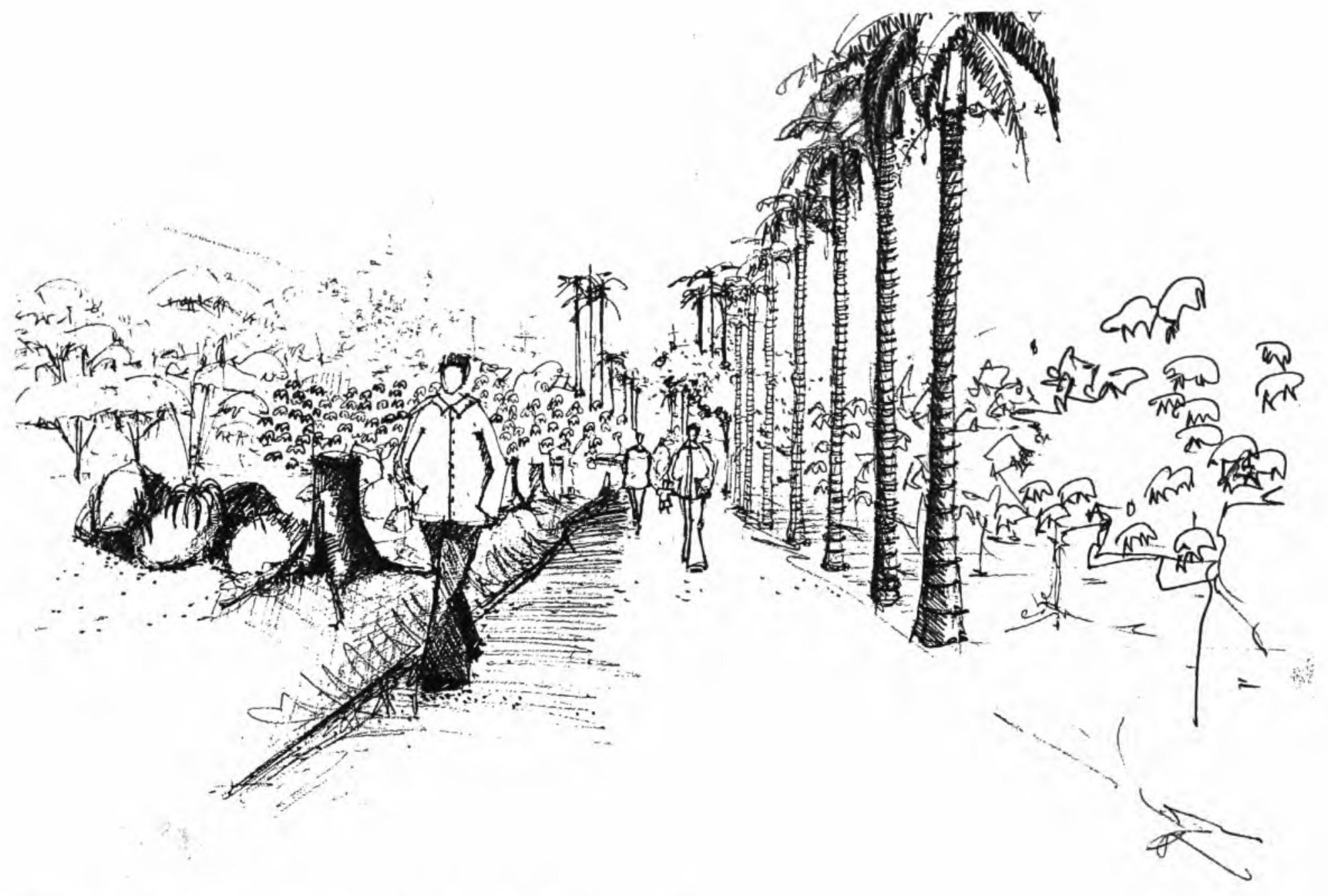

Caminho: Envolvimento em um dos lados com liberdade visual

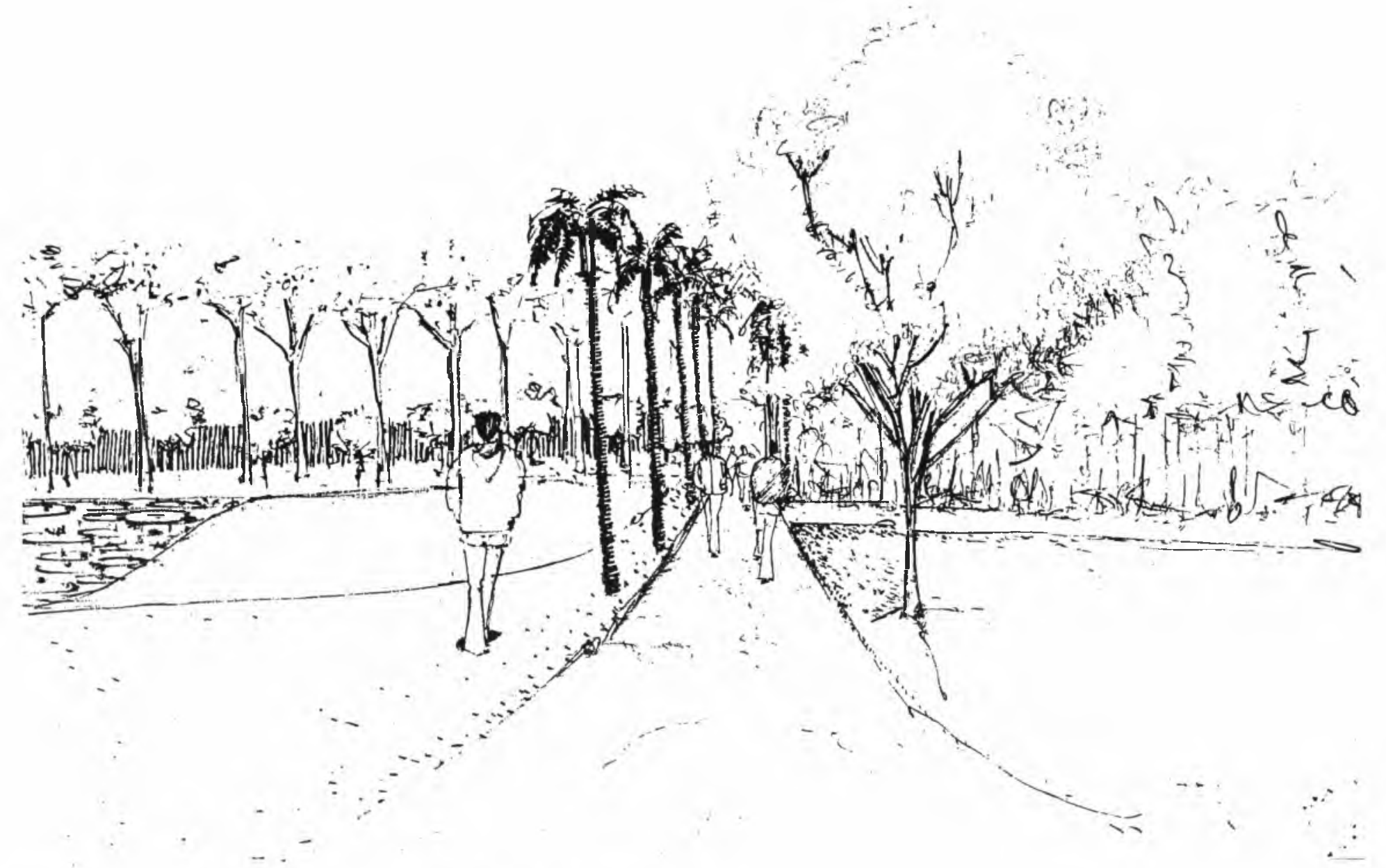




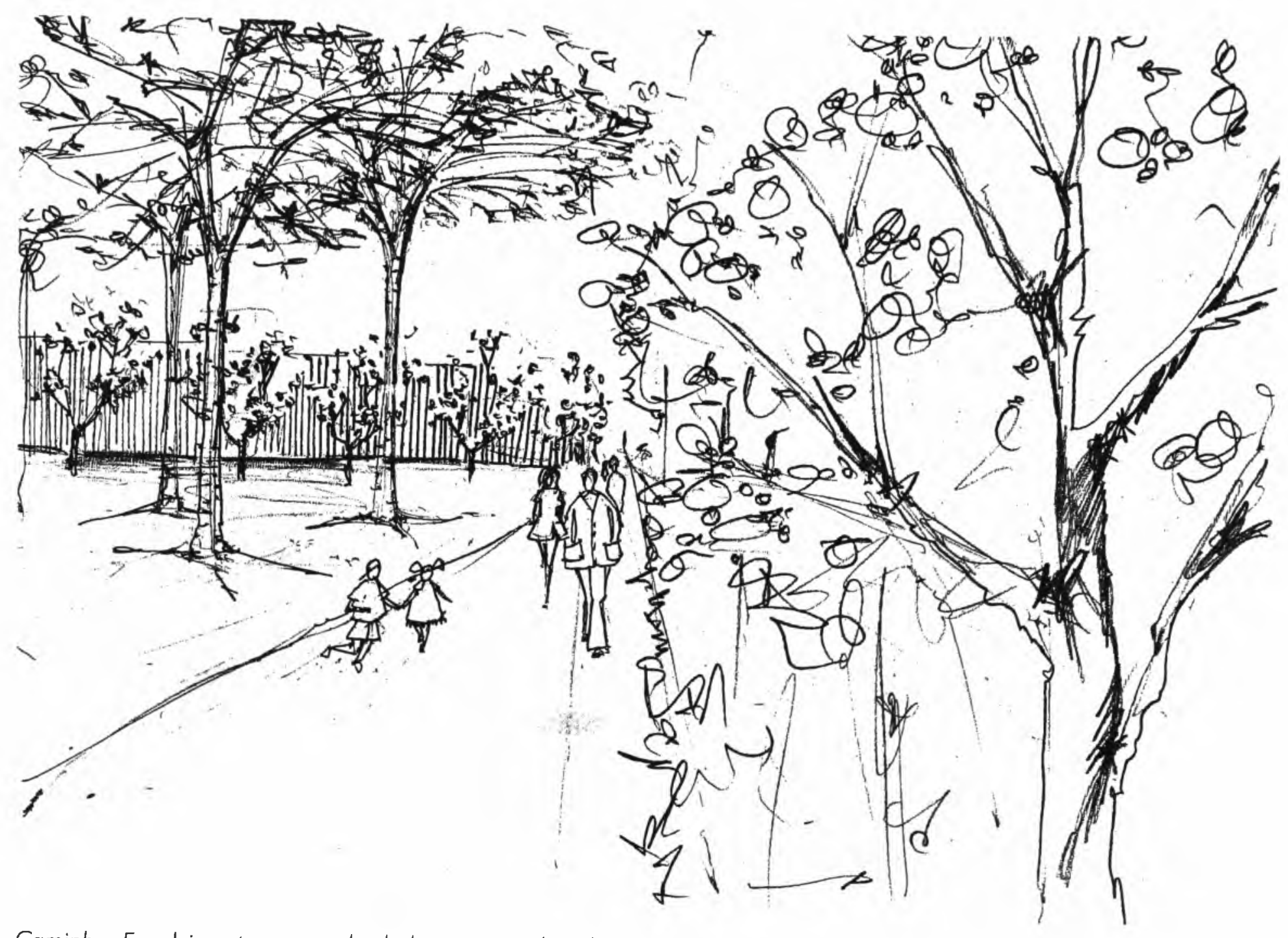

Caminho: Envolvimento em um dos lados e acima da cabeça

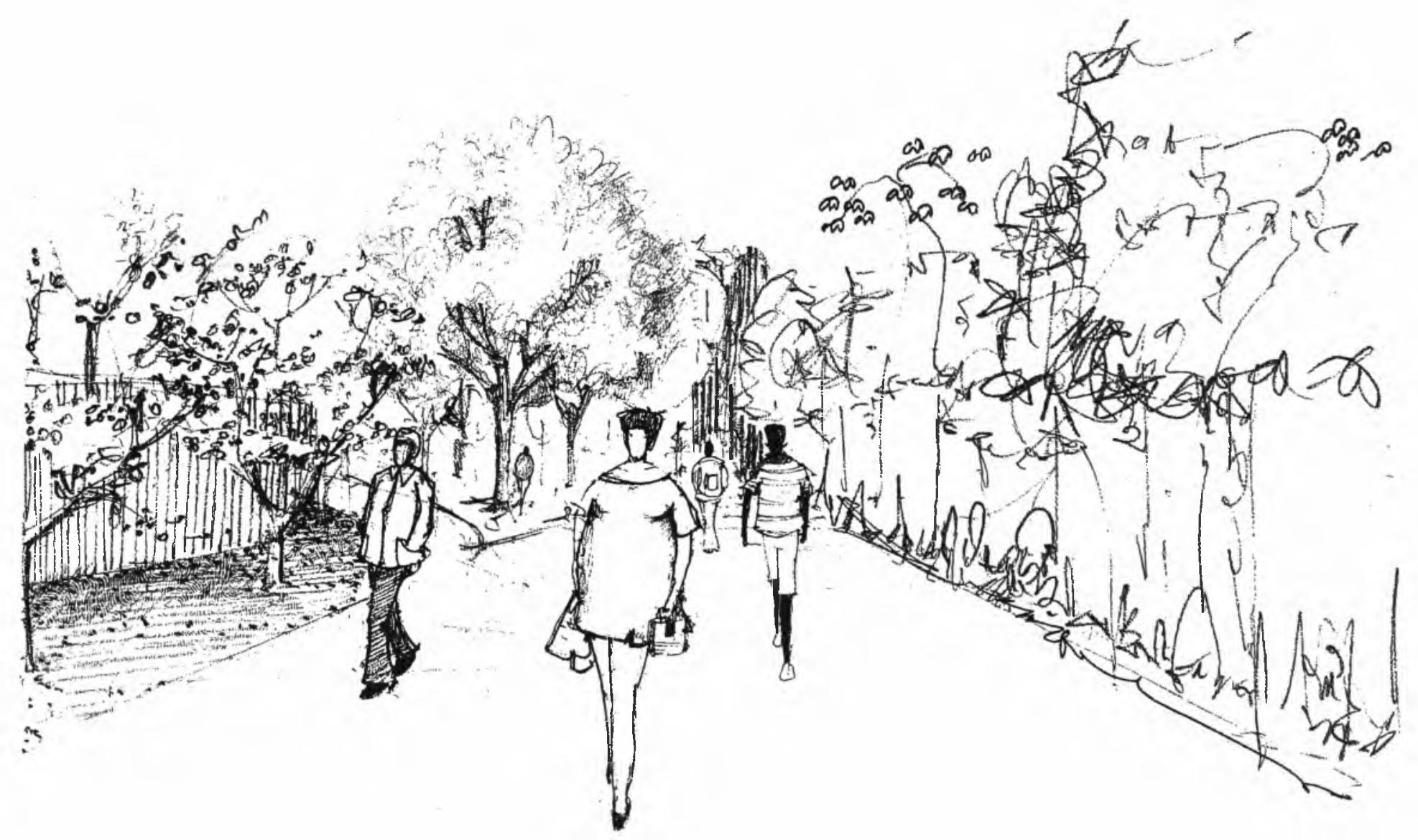




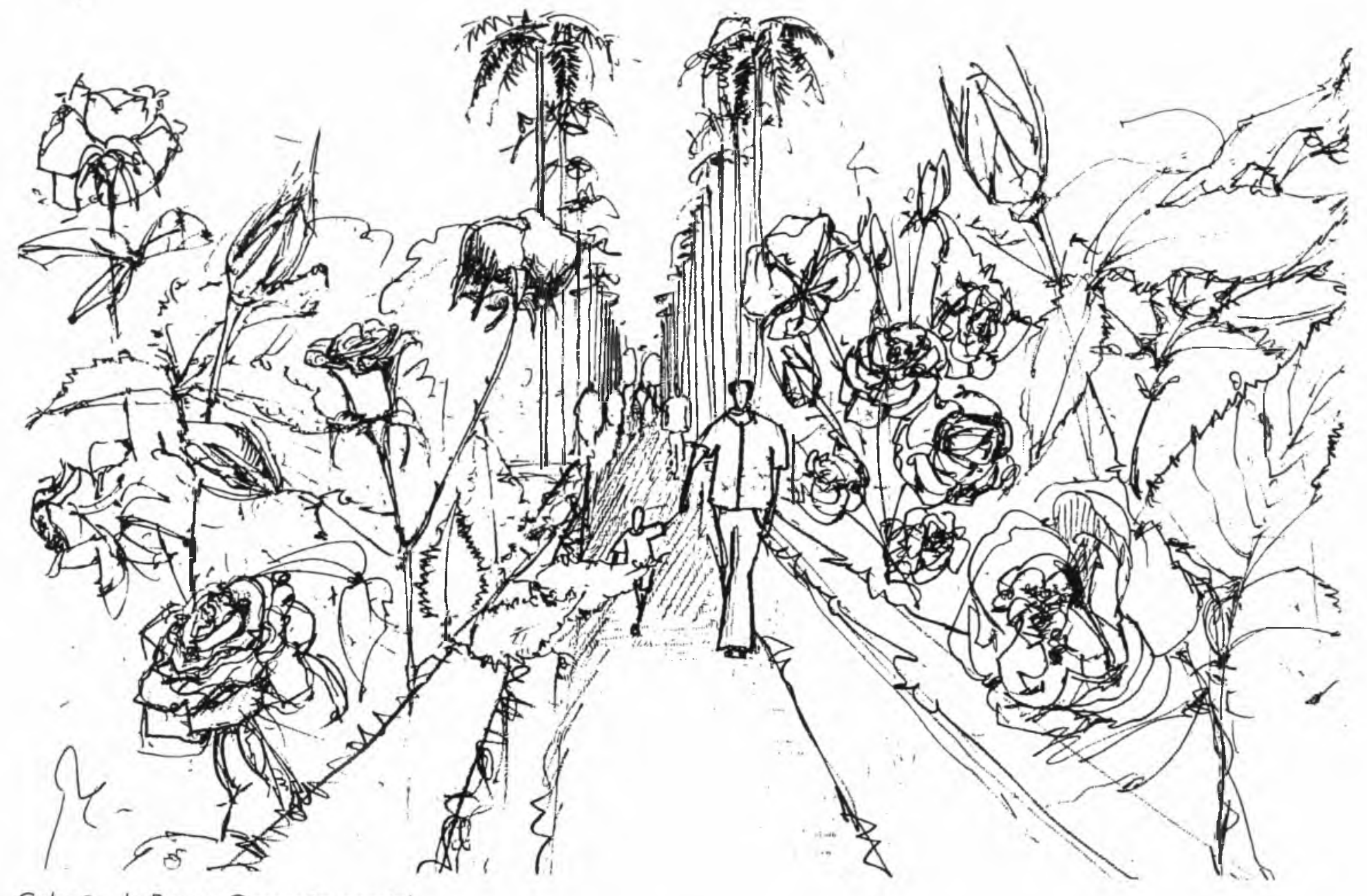

Coleçâo de Rosas: Opressão parcial

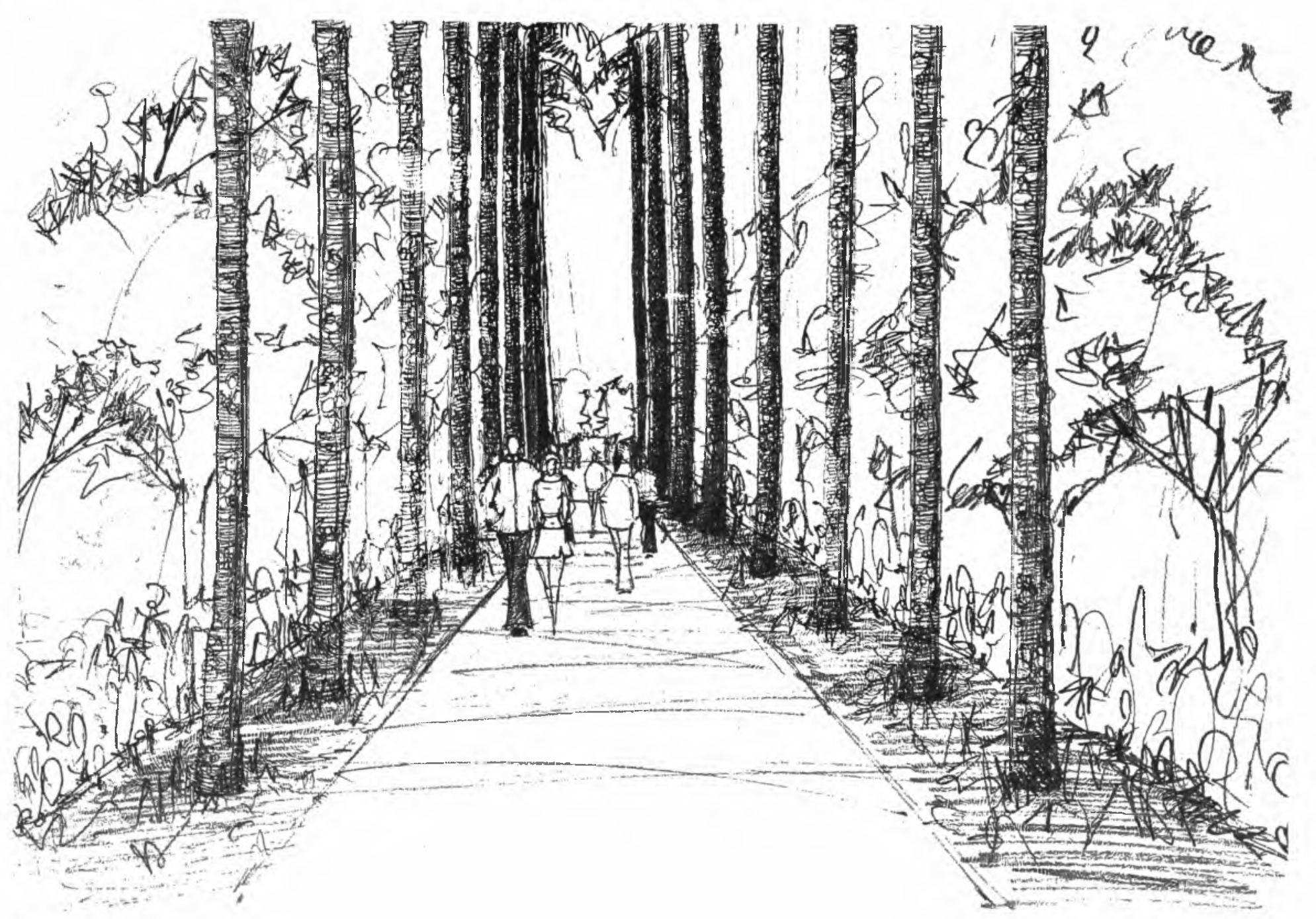

Caminho: Opressão 


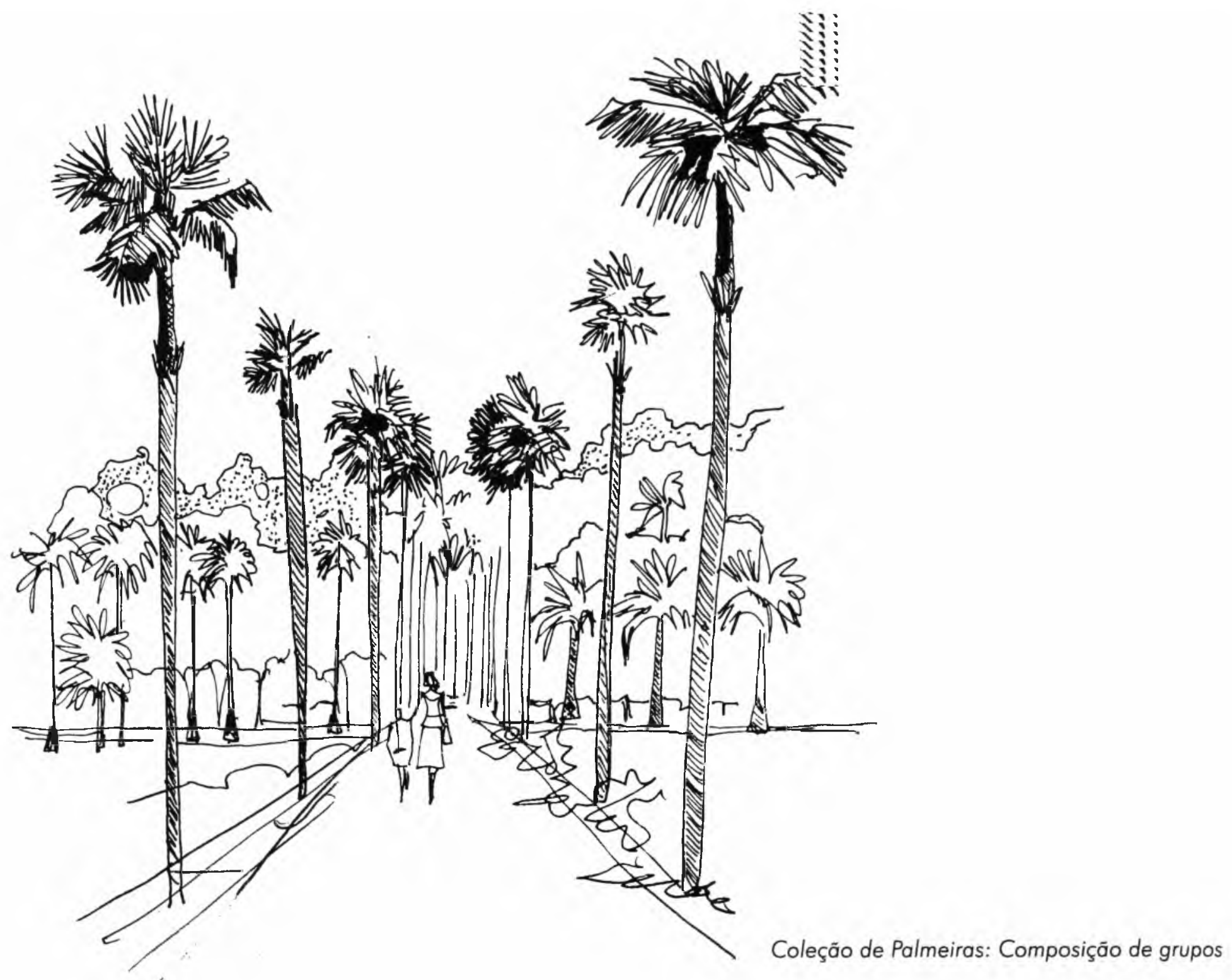

\section{Conclusão}

Faz-se o desenho da paisagem a partir da composição de elementos de formas naturais organizados de modo artificial. Compor uma paisagem não é reproduzir a forma em que ela se encontra na natureza, mas sim adequá-la às necessidades humanas. Para Marta Morengo de Tapia, a paisagem é um conjunto cujo efeito deriva das relações entre os distintos elementos. Elementos do cenário, sensíveis e complexos: luz, tons, cores, texturas.

Em um jardim podemos exercer a percepção com todos os sentidos. $\bigcirc$ perfume e a cor das flores, a forma das árvores, a textura dos troncos e das folhas e o canto dos pássaros podem estar presentes, induzindo sensações distintas. Sobre outro aspecto, a riqueza dos elementos componentes do jardim permite-nos trabalhar a percepção humana em diversas escalas, desde a impressão que se pode ter do jardim como um todo até a visāo de um pássaro ou de uma flor, passando pela sensação percebida em cada ambiente criado.

108 Nas palavras de Laura Conti: "Não queremos um mundo árido e fétido, mas sim um mundo com ar limpo, águas claras, terra negra e fértil, animais abundantes e variados. Queremos um mundo vivo, um mundo são, e também - por que não - um mundo belo." 


\section{Bibliografia}

CHING, Francis. Arquitetura: Forma, espaço e ordem. São Paulo: Martins Fontes, 1998.

FRANCO, Maria de Assunção Ribeiro. Desenho ambiental - Uma introdução à arquitetura da paisagem como paradigma ecológico. São Paulo: Anna Blume, 1997.

LEENHARDT, Jacques. Nos jardins de Burle Marx. São Paulo: Perspectiva, 1994. MONTEIRO, Marta Iris. Burle Marx - Paisajes liricos. Santiago do Chile: Editora Fernando Arce, 1997.

PAISAGEM E AMBIENTE: ENSAIOS. Sāo Paulo: FAUUSP, n. 5, 1986. . São Paulo: FAUUSP, n. 3, 1989.

PALAZZO Jr, José Truda, BOTH, Maria do Carmo. A natureza no jardim. Porto Alegre: Sagra, 1989. 